\title{
NINGUÉM QUER PERDER UM FILHO - Reações dos familiares observadas pela enfermagem ${ }^{1}$
}

\author{
NOBODY WANTS TO LOSE A CHILD - NURSING OBSERUATIONS ON RELATINES' \\ REACTIONS.
}

\section{Luiza Jane Eyre Xavier de Souza ${ }^{2}$ Maria Grasiela Teixeira Barroso ${ }^{3}$}

\begin{abstract}
RESUMO: A presença de produtos veterinários no interior dos domicílios sem os cuidados mínimos de segurança adotados, propiciou um caso de intoxicação exógena, em uma criança de 1 ano e 3 meses, que desenvolveu reação sistêmica grave, tendo sido acompanhada na Unidade de Terapia Intensiva Pediátrica de um hospital público, no município de Fortaleza. O objetivo do estudo consistiu em identificar as reações da família frente à intoxicação exógena na criança e analisar as reações da família, interpretando o seu contexto sócio-cultural. Desenvolveu-se como estudo de caso etnográfico, constando das fases de exploração, decisão e descoberta. Observou-se através dos resultados que a família conhece a existência dos fatores de risco no ambiente doméstico mas não adota medidas preventivas coerentes com esse conhecimento. Acredita-se que a redução dessas ocorrências exigem ações educativas transformadoras que levem as famílias a se conscientizarem da problemática que envolve a intoxicação exógena, em crianças, acontecidas sob sua responsabilidade
\end{abstract}

UNITERMOS: Educação e prevenção - Reações família - Intoxicação exógena

\begin{abstract}
The presence of veterinary products in the houses without any minimum security procedures has led to a poisoning case for a one-year old child who developed a serious systemic reaction. This child was interned at a Pediatric Intensive Care Unit at a public hospital in Fortaleza, Ceara. This study aims at identifying the family reaction facing a poisoning of a child and analyzing these reactions, interpreting its social cultural context. It has been developed as an ethnographic study case, consisting of the exploration, decision and discovery phases. It has been observed through the results that the family recognizes the existence of risk factors in home environment but does not adopt any coherent preventive methods with this experience. We do believe that these occurrences reduction demand transforming educative actions which may lead the family to be conscious towards the problematic that concerns poisoning for children, occurred under their responsibility.
\end{abstract}

KEYWORDS: Education and prevention - Familiar reactions - Outward poisoning.

\footnotetext{
${ }^{1}$ Trabalho apresentado no $9^{\circ}$ SENPE - Vitória-ES, julho de 1997.

2 Mestra em Enfermagem, Enfermeira do Instituto Dr. José Frota, Profa da Universidade Estadual do Ceará-FUNCAP.

${ }^{3}$ Prof Emérita da Universidade Federal do Ceará.
} 


\section{INTRODUÇÃO}

Notamos que o ambiente exerce grande influência na determinação de processos patológicos $\mathrm{e}$, por que não referir, algumas vezes letais. Marcondes et al. ${ }^{4}$ nos mostram que 0 ambiente é constituido pelos fatores bióticos, abióticos e os psico-sócio-culturais e comentam que o relacionamento da criança com esse ambiente tem uma importância que transcende a verificada pelo adulto.

Em estudo realizado, Souza ${ }^{7}$ salienta que as intoxicações exógenas se apresentam como um dos principais acidentes domésticos envolvendo crianças e alcançaram uma dimensão preocupante, principalmente nas menores de 5 anos. Na sua grande maioria, é acidental, porém, decorrente das situações facilitadoras, das características peculiares às fases da criança, de comportamentos inadequados da família e de pouco incentivo às medidas e aos comportamentos preventivos.

Descrevendo sobre intoxicação exógena em criança, Schvartsman 5,6 enumera alguns fatores gerais envolvendo o acidente tóxico, como a ignorância das pessoas em relação aos produtos, aliada ao intenso consumo, o que induz à imprudência e à negligência desses consumidores. A tecnologia também tem contribuído com um grande número de substâncias e seus efeitos complexos; a falha do adulto na proteção à criança e a manutenção de hábitos culturais enraizados interferem na adoção de cuidados preventivos.

Portanto, a presença de produtos veterinários no interior dos domicílios propiciou um caso de intoxicação exógena em uma criança de 1 ano e 3 meses, que desenvolveu reação sistêmica grave e foi acompanhada na Unidade de Terapia Intensiva Pediátrica do Instituto Dr. José Frota, no municipio de Fortaleza. A criança experimentou o trauma da hospitalização, a angústia do ambiente desconhecido, procedimentos dolorosos e sua familia conheceu a sensação de perda iminente presenciando e acompanhando a gravidade do quadro tóxico na criança.

A nossa realidade delineia um perfil assustador em relação às intoxicações exógenas. Durante os anos de 1992 a 1996, de acordo com os dados estatísticos do Centro de Assistência Toxicológica do Ceará - CEATOX, localizado no Instituto Dr. José Frota, foram registrados 4.436 atendimentos a crianças na faixa etária de 0 a 14 anos, sendo os medicamentos, os produtos químico-industriais e os de higiene doméstica os causadores da maioria dessas intoxicações.

Acredita Souza ${ }^{7}$ que a população deve ser conhecedora dos riscos que permeiam o ambiente doméstico e que esteja mais preparada para evitá-los. A enfermeira(o), como membro da equipe de saúde e profissional do cuidado, 
pode e deve resgatar seu papel de educador(a) e transformador(a) de ações, explicitando seu papel social, ocupando seu espaço na promoção e manutenção do estado saudável do ser humano no contexto familiar.

\section{OBJETIVOS}

Diante do que foi exposto, o estudo teve como objetivos:

- identificar as reações da família frente à intoxicação exógena na criança;

- analisar as reações da familia, interpretando o seu contexto sóciocultural.

\section{METODOLOGIA}

Por estarmos receptivas a partilhar a realidade do fenômeno pesquisado mediante a experiência dos informantes envolvidos, escolhemos a pesquisa qualitativa e, dentro desta, o estudo de caso etnográfico.

$\mathrm{O}$ caso em estudo foi realizado com a familia de uma criança, de 1 ano e 3 meses, que foi atendida na Emergência Pediátrica de um hospital de emergência, na cidade de Fortaleza, com quadro de intoxicação exógena por pesticida e que desenvolveu uma reação sistêmica grave, necessitando de cuidados na Unidade de Terapia Intensiva Pediátrica, por um período de 4 dias. $\mathrm{O}$ estudo desenvolveu-se por um período de 6 meses extendendo-se ao domicilio dos informantes-chave e constou das fases de exploração, decisão e descoberta segundo orientação de Lüdke \& André ${ }^{3}$.

Na primeira fase, foi estabelecido o contato inicial com a família, realizada a seleção dos informantes e a delimitação do fenômeno a ser investigado. Deu-se início ainda no ambiente hospitalar, com o primeiro contato entre pesquisadora e informante, e continuou no domicílio da família com realização de observações para adquirirmos uma visão geral do contexto familiar e ambiente sócio-cultural.

A segunda fase foi desenvolvida pela utilização do instrumento de coleta, entrevista etnográfica semi-estruturada, que compreendia perguntas descritivas e estruturais que contemplavam o fenômeno investigado.

A terceira fase foi realizada mediante a descrição da realidade encontrada com uma interpretação do contexto familiar e sócio-cultural.

Em todas as fases da pesquisa respeitamos a privacidade dos informantes como também fizemos a validaçãn dos dados. 


\section{RESULTADOS}

\section{O ambiente e a familia Camargo}

Na família Camargo, aconteceu uma intoxicação exógena com Álvaro, uma criança de 1 ano e 3 meses, que deu entrada na Emergência Pediátrica, no dia 14 de junho de 1996, às 19:50 h, com hipótese diagnóstica de intoxicação exógena e, segundo a mãe, a criança ingeriu remédio para banhar cachorro (carrapaticida), apresentando sonolência. O tóxico pertence ao grupo dos piretróides, pesticidas/herbicidas, ectoparasitário, conhecido comercialmente como Ticktraz-C, cuja substância química é a amitrazina. Álvaro foi atendido na emergência pediátrica e transferido para a Unidade de Terapia Intensiva Pediátrica, apresentando reação sistêmica grave como bradicardia e depressão respiratória, não respondia às solicitações verbais e lá permanceu durante 4 dias com boa evolução.

A família Camargo é composta por quatro membros, Alberto e Áurea, que são os pais, Amanda e Álvaro os filhos do casal. Moram na zona sul da cidade, em um bairro populoso, com muita área verde e casas em construção. $A$ rua não é asfaltada, há esgoto a céu aberto evidenciando que o bairro não foi saneado. $A$ casa tem cinco cômodos e está em fase de acabamento. Dispõe de poucos móveis, a cozinha é espaçosa e está sempre bem organizada. Porém, a casa é localizada em um grande terreno que é ocupado por pessoas da família, como irmãos, cunhados, sogra, formando, na realidade, uma grande familia que vive em constante interação.

A familia Camargo convive com o alcoolismo do Alberto e com suas inconstantes atividades de trabalho, o que ocasiona sérios momentos de privações econômicas e sociais que repercutem em toda a dinâmica da vida familiar. Áurea sempre reclama de tudo isso, mas, em determinados momentos, esboçava um certo conformismo. Informa que procura cuidar dos seus filhos da maneira que pode e freqüenta o Posto de Saúde, junto ao Programa do Desnutrido, para angariar alimentos para a família. Desta forma, consegue leite, açúcar, massa de milho, óleo de cozinha, arroz, o que ameniza a fome da família.

Apesar da situação que vivencia, Áurea elogia o marido e justifica que todos os momentos difíceis que enfrentam é pelo vício do álcool de Alberto porque quando ele não está bêbado, é o melhor homem do mundo. A pouca escolaridade também está presente na familia, mas os pais são conscientes de que devem manter os seus filhos na escola e acham que hoje é até mais fácil educá-los porque conseguem o material escolar gratuito.

$\mathrm{O}$ acesso à residência da família Camargo é muito fácil. Segue-se através de uma das principais avenidas da Cidade, que leva ao sentido sul, com grande 
tráfego de linhas de ônibus interligando a Capital, mediante os terminais urbanos. Quando nos aproximávamos da residência, as pessoas já conheciam e sabiam que a enfermeira que cuidou do Álvaro já vinha fazer a visita. Sempre éramos recebidos com muita amabilidade e passávamos bons momentos juntos, tanto no período da manhã como na parte da tarde. Fazíamos, questão de deixá-los muito à vontade e, sem pressa, inciávamos os pontos específicos do estudo, quando ficávamos, sem estranhos, com a família Camargo. Percebiamos a satisfação demonstrada pela familia em participar da pesquisa e saber que estavam sendo valorizados.

\section{O diálogo com os informantes}

A partir desses momentos de interação familiar sentimos a necessidade de nos aprofundarmos sobre os objetivos do estudo e passamos a realizar entrevistas semi-estruturadas, com os informantes-chave da família, representados pelos pais.

Sobre como a família reagiu à intoxicação exógena com o seu filho Álvaro, podemos observar, inicialmente, que a mãe e o pai não faziam idéia do que tinha acontecido e nem conseguiam explicar a reação da criança.

Foi mais ou menos assim às cinco e meia da tarde eu estava aí fora com ele né, e a minha sogra também estava sentada aí. Aí eu vou entro prá pegar o balde prá ir buscar água, aí quando volto pego ele e vou banhar; quando eu banho ele que enxugo e enrolo na toalha, o menino tava desmaiando assim, uma soneira, e ele tinha já dormido de tarde era muito. Aí o Alberto disse que o menino não estava bem não; ele dormiu foi muito, não é possivel que esteja com sono uma hora dessa. Aí minha sogra foi e disse que viu a menina botando uma gotinha assim na tampa e escorrendo assim na boca dele ai foi ela jogou o vidro no calçamento e fomos juntar aí era o vidro de banhar cachorro, prá matar carrapato né, pulga, ai pronto foi escurecendo, a comadre Mércia foi e levou ele, eu mesmo estava pensando que ele ia era morrer.

O sentimento de perda é muito forte porque a intoxicação exógena causa uma reação sistêmica e a sintomatologia aproxima com a realidade de morte iminente. O ambiente das Unidades de Terapia Intensivas, caracterizado pelos aparelhos e equipamentos de alta tecnologia e desconhecidos pelas familias, faz com que imaginem que não há mais esperança para o seu filho.

Quando eu cheguei lá, não sei não, me deu uma coisa tão ruim, que a assistente social disse que o problema dele era muito grave, muito grave mesmo. Aí quando eu cheguei lá e que vi ele todo ligado de aparelho eu nem pensei que ele ia escapar; mas graças a Deus, Deus é grande né, tem poder... Ele (o pai ) em tempo de ficar doido pensava que o filho dele ia morrer, mas graças a Deus passou. 
A religiosidade também está muito forte no contexto familiar e acreditam que Deus é misericordioso, tem piedade, que ajuda na recuperação, porque Ele também é pai.

Foi bem cuidado lá, graças a Deus tinha muita fé, no hospital também, fiquei com muito fé nele e nas pessoas que trabalhavam lá, tudo gente boa mesmo, mas graças a Deus que ele não papocou, porque ninguém quer perder um filho, né ?

Ao opinarem sobre quais os fatores que contribuem para a criança se envenenar, relataram que o descuido das pessoas responsáveis é um dos principais, como também a fase de desenvolvimento da criança que é caracterizada pela curiosidade, criatividade, sem que possua a verdadeira noção do perigo.

É negócio... é descuido mesmo, às vezes deixa assim um vidro, um desinfetante, menino não pode ver vidro o negócio é botar na boca né, vai vê outro tá brincando não tem muito juízo, vai inventa..., como nuns tempo desse eles estavam brincando aqui no quintal e traziam comprimido lá do lixo, era remédio, injeção, aqueles tubos de injeção né, aí enchiam d'água e aí um passavam na bunda do outro prá dar injeção; outro queria dar os comprimidos porque nós juntamos foi muito e jogamos no mato. Mas se não tivesse, já tinha morrido um bocado aqui no quintal, porque se junta um bocado de menino prá brincar de doutor, de médico (risos), com esse médico quase que arrombavam esse daqui, viu?

A familia Camargo acha que alguma coisa mudou no cuidado com as crianças, depois do envenenamento com seu filho.

Acho que mudou sim, né, que a gente tem mais cuidado, negócio de vidro, de remédio, não deixar mais fácil, tive mais cuidado, qualquer coisa agora eu já me lembro do que aconteceu, negócio de remédio, não botar fácil, botar num canto que eles mesmo não peguem..., essa daqui (Amanda) tem 7 anos mas se der um remédio, se ela pegar um remédio e for doce, ela diz que é doce, porque é doce, é assim...

A familia tem noção sobre como evitar esse tipo de acidente e acredita que - cuidado, compreendido como uma vigilância mais acurada durante o crescimento e desenvolvimento da criança, seja uma das maneiras mais eficazes para reduzir essas ocorrências.

Eu acho que é cuidado mesmo, não deixar ao alcance da criança. Eu acho que é os cuidados dos remédios, não deixar ao alcance deles, guardar bem guardado, porque esse daqui é doido por remédio doce, se outro abrir se der prá ele e for doce ele bebe todinho, que é doce... Ela também é do mesmo jeito. Mulher remédio não é assim não, tem que tomar na medida certa, não pode dá 
mais do que isso não, é desse jeito... Ai quer dizer se for um remédio forte é arriscado até morrer também né, é tipo um veneno, por isso todo cuidado, qualquer tipo de remédio.

O que representou para a familia presenciar o filho envenenado foi expressado como um fato que despertou a necessidade de se ter mais atenção e cuidado no desenvolvimento físico e nas necessidades emocionais e sociais da criança.

Eu acho..., ter mais cuidado com ele e que não é só envenenamento. Mas foi uma atividade prá mim ter mais cuidado nele e nela também né, todos dois. Se tiver também um vizinho, eu vendo, não vou deixar também fazer né, eu já vi o que eu passei também pelo meu..

\section{CONSIDERAÇÕES FINAIS}

Investigar sobre acidentes tóxicos, que ocorrem no interior da familia e sob sua responsabilidade, é um tema que está permeado de ambigüidades, ou seja, de sentimentos de culpa pelo acontecido, do julgamento das pessoas em relação à negligência e descuido dos adultos responsáveis em proteger e cuidar da criança e de manifestações de felicidades pela recuperação da criança após $o$ acidente tóxico.

Porém, em nenhum momento, a familia nega que não se descuidou; afirma que depois do acontecido passou a ser mais cuidadosa e que, de certa forma, serviu para alertá-los sobre os perigos que existem no ambiente doméstico.

Demonstram, verbalmente, que têm noção de como agir para minimizar esses casos mas, na verdade, não é o que encontramos no seu ambiente natural; desta forma, existe uma incoerência no que a família diz e o que a família faz. É preciso, como preconiza Freire, ${ }^{2}$ que as pessoas repensem as suas ações e que sejam capazes de transformações sociais.

Acreditamos que ações educativas permanentes devem constar das políticas sociais e que os profissionais que compõem as áreas de saúde e educação devem exercer sua capacidade para mobilizar e viabilizar essas ações. Para Abad, ${ }^{1}$ a enfermeira (o) tem grande potencial para elaborar e desenvolver abordagens preventivas junto à familia e comunidade sobre os acidentes que acontecem no ambiente doméstico.

Concordamos que uma mobilização conjunta dos profissionais que lidam com famílias devem realizar informações sobre os fatores de risco no ambiente doméstico e sobre as fases de crescimento e desenvolvimento infantil, para que possamos, deste modo, contribuir para a redução dessas indesejáveis ocorrências. 


\section{REFERÊNCIAS BIBLIOGRÁFICAS}

1. ABAD, Ana M. Cordero et al. Accidentes Mas Frecuentes en el Hogar. Papel de la Enfermera. Rev. Cubana Enfermer. v. 5, n. 3, p. 203-216, septiembre-diciembre, 1989.

2. FREIRE, Paulo. Educação e Mudança. 19 ed. Rio de Janeiro-São Paulo: Paz e Terra, 1993, 79 p.

3. LÜDKE, Menga, ANDRÉ, Marli E. D. A. Pesquisa em Educação: Abordagens Qualitativas. São Paulo: EPU, 1986, 99 p.

4. MARCONDES, Eduardo et al. Os Fatores Ambientais (Ecopediatria). In: MARCONDES, Eduardo. Pediatria Básica. 7 ed. v. 1, São Paulo: Sarvier, 1987, 799 p., p. 14-27.

5. SCHVARTSMAN, Samuel. Acidentes na Infância. In: CARVALHO, Oreste. Manual de Pediatria. Rio de Janeiro, Editora Guanabara Koogan, 1977, 1081 p., p. 942-945.

6. Intoxicaçōes Agudas. 4 ed., São Paulo:Sarvier, 1991, $355 \mathrm{p}$.

7. SOUZA, Luiza Jane Eyre Xavier de. Envenenar é Mais Perigoso - Uma Abordagem Etnográfica. Fortaleza: UFC, 1997, 152 p. Dissertação (Mestrado), Curso de Mestrado em Enfermagem da Universidade Federal do Ceará, 1997. 